\title{
Utilization of a dynamometric pendulum to estimate cutting forces involved during routing. Comparison with actual calculated values
}

\author{
Florent EYMA ${ }^{\text {a* }}$, Pierre-Jean MÉAUSOONE $^{\mathrm{b}}$, Pierre LARRICQ $^{\mathrm{a}}$, Rémy MARCHAL $^{\mathrm{c}}$ \\ a IUT Paul Sabatier, 1 rue Lautréamont, 65000 Tarbes, University of Toulouse, France \\ ${ }^{\mathrm{b}}$ ENSTIB, 27 rue du Merle Blanc, 88000 Épinal, University of Nancy, France \\ ${ }^{c}$ ENSAM Cluny, rue Porte de Paris, 71250 Cluny, France
}

(Received 5 October 2004; accepted 14 March 2005)

\begin{abstract}
Nowadays, to measure cutting forces involved during routing, systems with piezo-electric sensors are generally used. This study began with the following observation: two species with the same density can induce completely different cutting forces. But two species with completely different densities can also show closed cutting forces. Current formulations used to calculate cutting forces can not explain such phenomenon. That is why some new research has been done to establish relationship between cutting forces and mechanical parameters [8]. In this work, we decided to present a very simple, quick and accurate method to obtain similar results and good cutting forces approximation using a dynamometric pendulum. With this method, we can take into account the machining parameters, wood characteristics, cutting speed, and impact resistance into just one test. It is possible to quickly know wood behaviour during machining, particularly when new species or new conditions are used in industries.
\end{abstract}

cutting forces prediction / dynamometric pendulum / routing / tropical woods

Résumé - Utilisation d'un pendule dynamométrique pour estimer les efforts de coupe en défonçage, comparaison avec les valeurs actuellement calculées. De nos jours, pour mesurer les efforts de coupe en défonçage, on utilise généralement des capteurs piézo-électriques. Cette étude a été lancée suite à certaines observations : deux essences avec la même densité peuvent demander des efforts de coupe complètement différents. Mais deux essences avec des densités complètement différentes peuvent également demander des efforts de coupe identiques. Les formulations actuellement utilisées ne permettent pas d'expliquer ces phénomènes. C'est pourquoi des travaux de recherche ont été réalisés pour établir des relations entre les efforts de coupe et les propriétés mécaniques du bois [8]. Dans ce travail, nous avons décidé de présenter une méthode simple, rapide et précise pour obtenir de bons résultats et de bonnes approximations des efforts de coupe en utilisant un pendule dynamométrique. Grâce à cette méthode, il est possible de tenir compte des paramètres de coupe, des caractéristiques du bois, de la vitesse de coupe et de la résistance aux chocs avec seulement un essai. Il est possible de connaître rapidement le comportement du bois pendant l'usinage, en particulier quand de nouvelles essences ou de nouvelles conditions de coupe sont utilisées dans les entreprises.

prédiction d'efforts de coupe / pendule dynamométrique / défonçage / bois tropicaux

\section{INTRODUCTION}

This work concerned the routing process $90-0[11,16]$, i.e., peripheral milling parallel to grain (longitudinal rotary cutting), very often used in secondary wood processing. Nowadays, companies have to improve their cutting process more and more (because of higher customer requirements, competition on a world-wide scale, market opening, etc.), and must use new wood species and products with optimal parameters: it is then, impossible to do "as usual" [6]. However, there is a lack of accuracy in the wood behaviour explanation during machining and chip formation. Quite often, we can find a gap of more than $80 \%$ between the cutting forces measured and the current methods using material coefficient or cutting energy [8]. One of the main reasons is the lack of knowledge concerning wood species influence on the force values: this factor remains very difficult to take into consideration. It is possible to find coefficients linked to specific gravity or moisture content measurement, but nothing else to obtain very accurate results $[12,14]$. Thus, to improve this situation, several routing trials have been performed.

The first study was to investigate the influence of various physical and mechanical characteristics on the wood behaviour during machining $[7,8]$. This method allowed us to obtain a new formulation introducing a new material coefficient $\mathrm{Km}$. Several authors have introduced mechanical characteristics to

\footnotetext{
* Corresponding author: florent.eyma@iut-tarbes.fr
} 


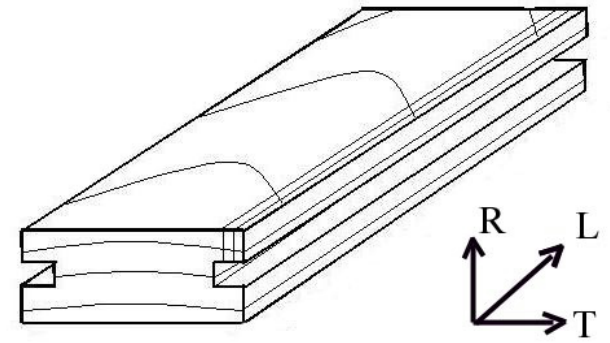

Figure 1. Wood specimen used for routing.

solve this problem [2, 3, 17], but these authors were concerned respectively with the cutting modes $0-90$ (relevant to peeling $[2,17]$ ), and 90-90 (relevant to cross-cutting [3]).

However, in the foregoing study, two factors remain difficult to deal with: cutting velocity and shocks generated when the tool cuts the wood. Therefore, another process was tested: the dynamometric pendulum.

Thus, the aim of this study was:

- to improve comprehension of wood behaviour during routing (chip formation, surface roughness, ...);

- to improve prediction of cutting forces;

- to take into account (more conveniently) tool speed, shocks and wood influence (fiber direction, specific gravity, ...);

- to compare results obtained with pendulum and routing machine.

\section{MATERIALS AND METHODS}

In order to obtain homogeneous characteristics for each wood species [7], it was decided to work on thirteen tropical woods and one European wood reference namely beech (Fagus sylvatica). The choice of 13 tropical woods was done with the "CIRAD Forêt" in Montpellier (France), among a large set of woods presenting a large range for specific gravity and mechanical characteristics. The moisture content of each wood specimen was fixed at $12 \%$ in order to obtain results close to literature values. Specific Gravity ( $\mathrm{SG}=\mathrm{Mo} / \mathrm{Vsat}$, i.e. "anhydrous mass/saturated volume") of each species was measured.

\subsection{Machining tests}

Cutting forces measurements were performed on a CNC router (Computer Numerically Control) using peripheral down-milling parallel to the grain. The sample size was: $22 \mathrm{~mm}$ in the tangential direction "T", $40 \mathrm{~mm}$ in the radial direction " $\mathrm{R}$ " and $135 \mathrm{~mm}$ in the longitudinal direction "L". A groove was made on the side of specimens in order to process only with the tool's edge and never with its top (Fig. 1).

Normal and tangential cutting forces are measured with a piezoelectric dynamometers attached to the router table as shown Figure 2. The resultant total cutting force is calculated for analysis. Machining parameters used are [1]:

$-\mathrm{N}=9000 \mathrm{rpm}$;

$-\mathrm{H}=2 \mathrm{~mm}$ (depth of cut);

$-\varnothing=14 \mathrm{~mm}$ (tool diameter);

$-\mathrm{V}_{\mathrm{f}}=4 \mathrm{~m} \mathrm{~min}^{-1}$ (feed speed);

$-b=9 \mathrm{~mm}$ (width of cut);

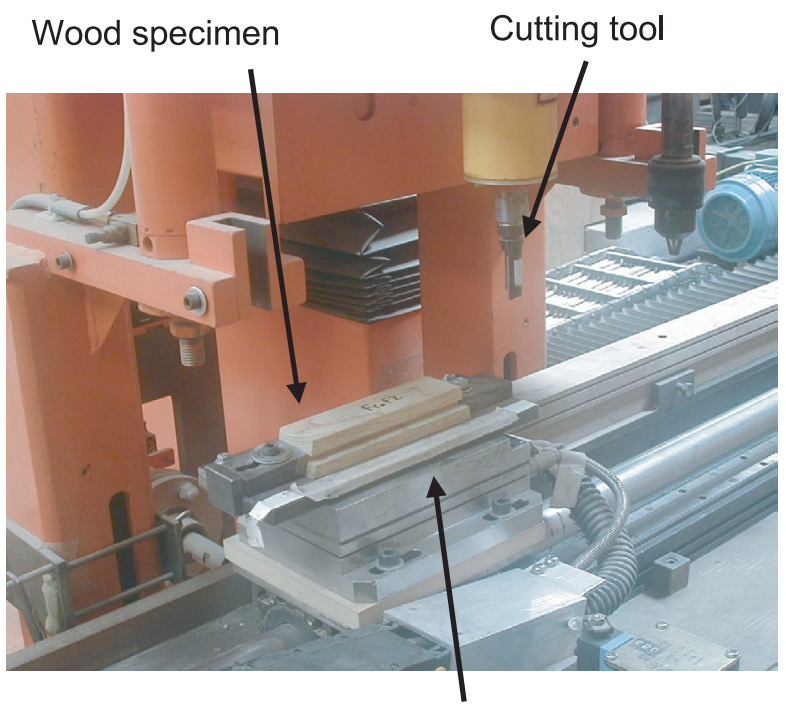

Piezo-electric sensors - Kistler table.

Figure 2. Specimen on router's table with its cutting forces measuring device.

- Straight edge: 1 tooth with only one tooltip engaged; rake angle: $23^{\circ}$; clearance angle: $15^{\circ}$.

Each value of total cutting forces obtained is a mean of 30 mean resultant values.

\subsection{Dynamometric pendulum adjustment}

It was in the first years of XVIII ${ }^{\mathrm{e}}$ century that Jacques Cassini showed the pendulum to be a good means to measure energy. It was only more recently $[4,23]$, that a dynamometric pendulum was used to measure wood cutting energy. Chardin worked mainly on sawing of European and tropical woods. Between 1962 and 1966, [20, 21, 25] and others, studied on wood cutting characteristics using a dynamometric pendulum.

However, for a long time, with the development of electronic means of measuring and recording cutting forces, the pendulum approach has been neglected. Thus, at the beginning of this work, it was decided to use one of Chardin's pendulums located currently at Ensam Cluny, France. Obviously, it was necessary to improve this pendulum. A device to get samples into position was added, a modification of tools holders and a chuck arrangement were made. A piezoelectric dynamometers was added, etc. Results are presented on Figures 3 and 4.

The principle of the measurement is very simple: a tool with only one tooth (width of $8 \mathrm{~mm}$ ) is fixed at the tip of a $1.2 \mathrm{~m}$ and $36 \mathrm{Kg}$ arm (Fig. 5). This arm is dropped always from the same height $\left(z_{0}\right)$. The first time, the measure is done idle in order to estimate loss of energy due to the friction (Eq. (1)).

$$
P=m \cdot g \cdot\left(z_{0}-z_{1}\right)
$$

where $P=$ lost of energy linked to the friction $m=$ arm weight.

For each wood species, ten measurements of cutting energy have been done reading the maximum angle obtained by the arm just after cutting $(\omega)$, (Eq. (2)):

$$
E_{\text {cutting }}=m \cdot g \cdot\left(z_{1}-z_{2}\right)=m \cdot g \cdot(\operatorname{Cos} \theta-\operatorname{Cos} \omega)
$$




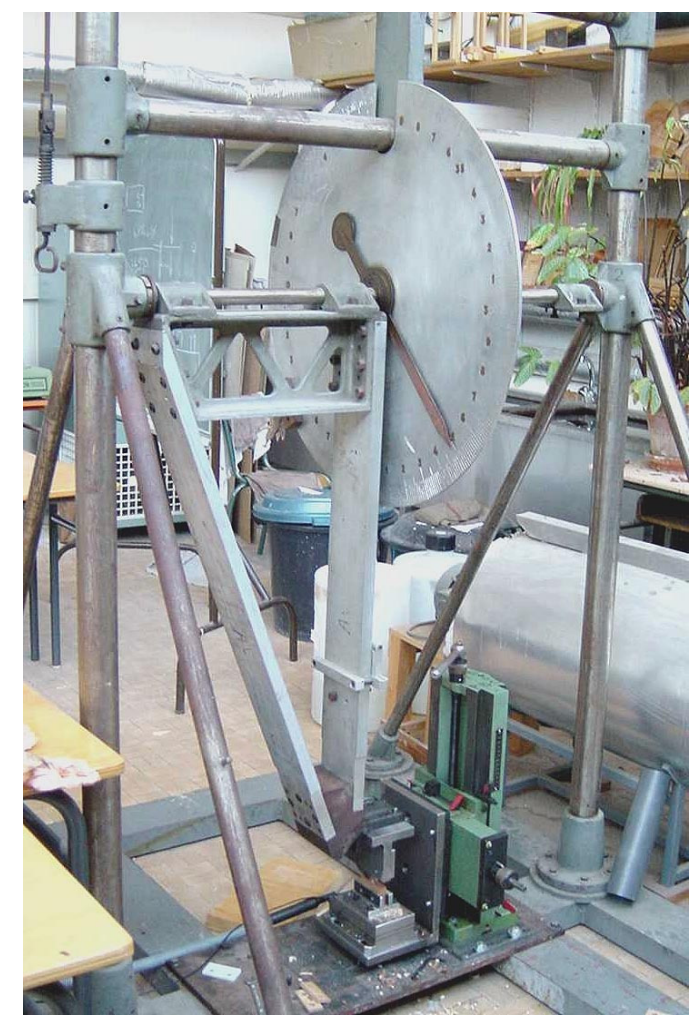

Figure 3. Dynamometric pendulum.
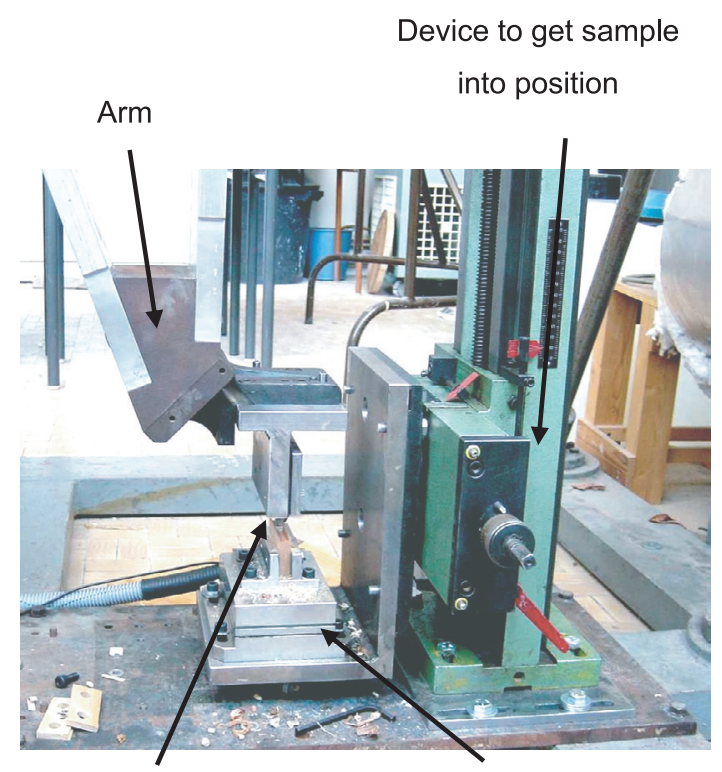

Tool with one tooth

Sample and piezo-electric

dynamometers

Figure 4. Details of pendulum arm and of device to get sample into position.

where $\mathrm{m}=$ arm weight $E_{\text {cutting }}=$ cutting energy measured; $\theta=$ angle obtained idle (without sample); $\omega=$ angle obtained after cutting.

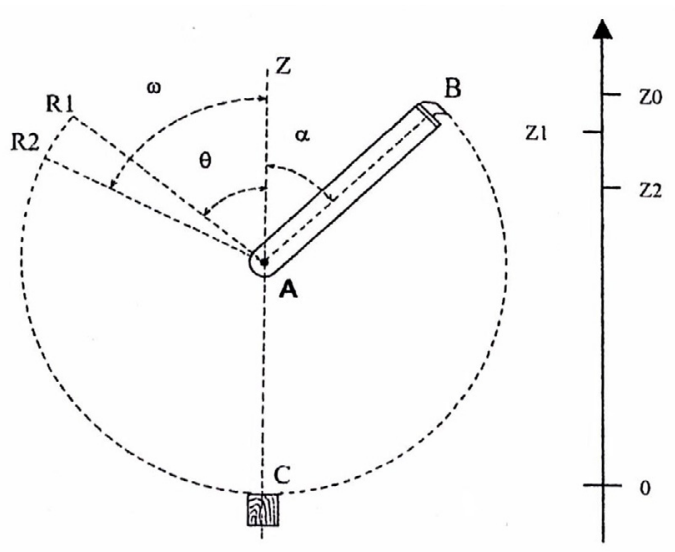

Figure 5. Use principle of dynamometric pendulum, where $Z_{0}=$ arm starting height. $Z_{1}=$ arm height after test without sample; $Z_{2}=$ arm height after test with sample.

The cutting energy is divided by sample length $\left(l_{\text {cutting }}\right)$ to obtain the mean total cutting forces $\left(F_{T}\right)$, (Eq. (3)):

$$
F_{\mathrm{T}}=\frac{E_{\text {cutting }}}{l_{\text {cutting }}} .
$$

Samples size is: $5 \mathrm{~mm}(\mathrm{~T}), 40 \mathrm{~mm}(\mathrm{R})$ and $140 \mathrm{~mm}(\mathrm{~L})$. Like for routing tests, a cutting speed of almost $7 \mathrm{~m} \mathrm{~s}^{-1}$ is used (like for routing tests). Moreover, similar cutting conditions were used (rake angle, clearance angle, cutting plane, etc.). The depth of cut has been decreased to $1 \mathrm{~mm}$ in order to obtain appropriate chip formation. Each value of cutting forces reported, is a mean of ten measurements obtained on each species.

This pendulum was adapted for easy adaptability: possibility of working with or without piezo-electric dynamometers, use of several workpiece fastening possible, etc. Thus, the aim of the present study was:

- Firstly, to compare pendulum results with values obtained using routers and piezo-electric sensors;

- Secondly, to find a cheaper and more convenient method not requiring computerized force recording, for rapid assessment of wood behaviour and cutting forces involved during machining.

\section{RESULTS AND DISCUSSIONS}

\subsection{Measurements on the router [9]}

At the beginning of this study, the aim was to take into account the influence of wood material in the estimation of cutting forces involved during routing. It was decided to work on wood mechanical properties involved during routing $[10,13$, 22, 24], namely: Monnin hardness, fracture toughness in mode I, shearing and compression parallel to the grain. Cutting forces have been measured on routers ( 30 values for each species). Tests results were combined, (different mathematical models were tested) and several models were obtained. The highest significant correlation was obtained for the following equation using three properties : $P_{\mathrm{f}, \mathrm{I}}$ (elastic parameter in fracture toughness), Ec (modulus of elasticity in compression), and $S G$ (specific gravity) (in order to know if each factor was significantly separate in the correlation, a student test " $t$ " was carried out). $F_{\mathrm{c}}$ is total cutting forces during routing. 


$$
F_{\mathrm{c}}=\left(0.00139 \cdot P_{\mathrm{f}, \mathrm{I}}\right)+\left(0.0031 \cdot \frac{E c}{S G}\right) .
$$

This model allowed an improvement of $30 \%$ of the coefficient of determination $\left(R^{2}=0.80\right)$ in the relation between predicted cutting forces and routing measurements, and a reduction of $60 \%$ of errors sum of squares. It takes into account wood species influence with the introduction of a new material coefficient " $K_{\mathrm{m}}$ ".

$$
K_{\mathrm{m}}=\left(5.73 \times 10^{-5} \times \frac{E c}{S G}\right)+\left(2.57 \times 10^{-5} \times P_{\mathrm{f}, \mathrm{I}}\right) .
$$

This coefficient " $\mathrm{Km}$ " allowed the use of the following equation described in Eyma's thesis to calculate cutting [8]:

$$
F_{\mathrm{c}}=F 1 \times \mathrm{b} \times K \mathrm{~m} \times K \mathrm{~h}
$$

where $F 1$ correspond to the influence of cutting process and chip thickness; $b$ is the width of cut and $K \mathrm{~h}$ is moisture content coefficient [14].

Moreover, it also permits to estimate more accurately which mechanical properties are mainly involved during routing; and even if generally, mechanical stresses depend on chip formation $[11,15,16,19]$, it appears clearly that, in routing, notions of crack propagations (with fracture toughness parameter), and cellular-wall mechanical strength (with the specific compression modulus) are especially important to understand cutting forces involved.

However, at that state of the study, the question was: is it possible to obtain the same precision more easily, without expensive material (piezo-electric sensors, router, etc.), and maybe with more information (on impact and speed influence)?

\subsection{Measurements using the pendulum}

$x$ Before beginning tests, the accuracy of measurements was estimated. Results showed a very high repetitivity with a variation coefficient of $0.1 \%$. These gaps are really non significative and can be explained by manual sample positioning and wood heterogeneity. Moreover, these results show that angular measurements made on pendulum are reliable and accurate.

$\boldsymbol{x}$ Then, the influence of cutting speed (varying with the pendulum arm height) was tested (Eq. (7)). Ten speeds, from 0.1 to 8 meter per second were used with two species : Beech (Fagus sylvatica) and Ipé (Tabebuia sp.).

$$
V_{c}=\sqrt{2 \cdot g \cdot L \cdot(1+\cos \alpha)}
$$

where $V_{c}=$ cutting speed $\left(\mathrm{m} \mathrm{s}^{-1}\right) ; \alpha=$ start angle of arm pendulum; $L=$ arm length (m); $g=$ acceleration due to gravity.

Results show that cutting speed does not have any influence on cutting forces observed. The same study was done on router and gave the same results (Fig. 6).

It confirms some other results $[11,14,16]$ but, is something contested by researchers of high-speed machining [5] where an increase of speed leads to a decrease of cutting forces involved. Then, in this study, cutting speed was chosen arbitrarily to be $7.6 \mathrm{~m} \mathrm{~s}^{-1}$.

x Influence of chip formation: In early tests, a depth of cut of $2 \mathrm{~mm}$ was used. However, for some wood species it occurred that chip tearing was excessive, and the analyze of cutting forces

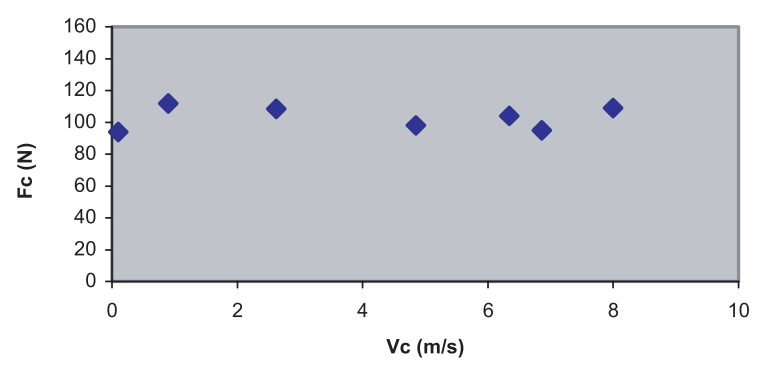

Figure 6. Cutting speed influence on cutting forces measured.

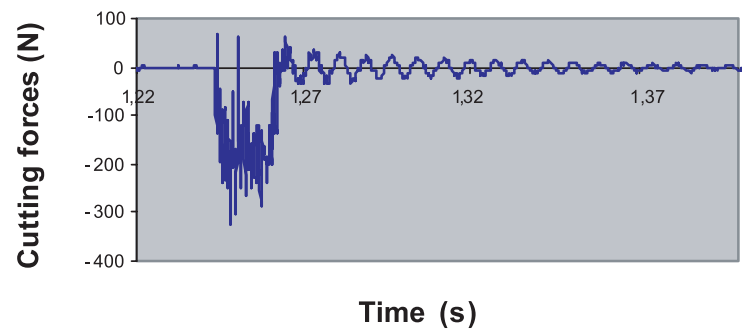

Figure 7. Cutting forces signal.

measured with piezo-electric sensors was impossible because of signal perturbations. Moreover, cutting forces measurements were very close to cutting forces measured with a $1 \mathrm{~mm}$ depth of cut. This phenomenon appeared for most wood species except for very hard wood like Ipé (Tabebuia sp.) or Boco (Bocoa prouacensis Aubl.). In these cases, with a depth of cut of $2 \mathrm{~mm}$, the cutting forces were twice as high, as expected.

These observations can be explained by something very important in machining: the "Good Cutting Area" [4]. It is not always possible to speak about wood cutting: in some conditions, beyond some depth of cut, beyond some cutting speed, there is no more chip formation, but wood tearing with successive cracking during chocks between wood and tool. Thus, in experimentation, it is always necessary to find optimal cutting conditions to have chip formation and to avoid wrong analysis. In industrial machining, this choice of optimal conditions can be done using the "Coupled Tool-Material" method for example [18].

The difference between wood species can be explained by chip formation mechanism. In the case of very hard woods like Ipé or Boco, chips obtained are fragmented (with a frequency of $300 \mathrm{~Hz}$ corresponding to a wood cracking each $2 \mathrm{~cm}$ ), whereas for the other wood species, chip is rolled, and regular splitting can be observed with a frequency of $600 \mathrm{~Hz}$.

Concerning measurements made with the piezo-electric dynamometer on the pendulum, it was observed on each cutting forces curve, residual perturbations (frequency of $150 \mathrm{~Hz}$ ) after cutting whatever the wood species and the depth of cut. Moreover, it appeared that cracking frequency on chip formation is always proportional to this same frequency of $150 \mathrm{~Hz}$ (Fig. 7). Thus, a very interesting possibility is to obtain cracking frequency (and then, surface roughness information) just observing the cutting forces signal [8]. However, these perturbations are not 
Table I. Comparison of cutting forces obtained on router $\left(F_{\mathrm{r}}\right)$ and pendulum $\left(F_{\mathrm{p}}\right)$.

\begin{tabular}{|c|c|c|c|c|c|c|c|c|}
\hline \multicolumn{3}{|c|}{ Wood species } & \multicolumn{3}{|c|}{ Cutting forces } & \multicolumn{3}{|c|}{ Comparison router / pendulum } \\
\hline Name & Scientific name & $S G$ & $F_{\mathrm{r}}(\mathrm{N})$ & $F_{[6]}(\mathrm{N})$ & $F_{\mathrm{p}}(\mathrm{N})$ & $F_{\mathrm{r}} / V_{\mathrm{r}}\left(\mathrm{N} \mathrm{mm}^{-3}\right) F_{\mathrm{p}} /$ & $V_{\text {pend }}\left(\mathrm{N} \mathrm{mm}^{-3}\right)$ & Difference $(\%)$ \\
\hline Fromager & Ceiba pentandra Gaertn. & 0.204 & 21.1 & 21.5 & 36.7 & 2.7 & 4.1 & 35 \\
\hline Ayous & Triplochiton scleroxylon & 0.315 & 30.5 & 25.7 & 47.3 & 3.8 & 5.3 & 27 \\
\hline Virola & Virola spp. & 0.418 & 36.7 & 34.4 & 57.1 & 4.6 & 6.3 & 27 \\
\hline Niangon & Tarrietia densiflora & 0.47 & 46.6 & 43.5 & 85.6 & 5.9 & 9.5 & 38 \\
\hline Grignon franc & Ocotea rubra & 0.485 & 28.9 & 31.8 & 51.9 & 3.6 & 5.8 & 37 \\
\hline Dodomissinga & Parkia nitida & 0.499 & 41.7 & 38.7 & 82.0 & 5.2 & 9.1 & 43 \\
\hline Frake & Tarminalia superba & 0.554 & 34.6 & 39.6 & 73.1 & 4.4 & 8.1 & 46 \\
\hline Beech & Fagus sylvatica & 0.573 & 33.2 & 34.5 & 78.7 & 4.2 & 8.7 & 52 \\
\hline Bagasse & Bagassa guianensis & 0.689 & 36.8 & 41.4 & 88.2 & 4.6 & 9.8 & 53 \\
\hline Eucalyptus & Eucalyptus globulus & 0.705 & 46.3 & 39.7 & 116.2 & 5.8 & 12.9 & 55 \\
\hline Moabi & Baillonella toxisperma & 0.714 & 35.1 & 37.1 & 75.9 & 4.4 & 8.4 & 48 \\
\hline Wacapou & Vouacapoua americana & 0.755 & 34.1 & 40.4 & 68.2 & 4.3 & 7.6 & 43 \\
\hline Ipé & Tabebuia sp. & 0.851 & 44.9 & 44.3 & 106.6 & 5.7 & 11.8 & 52 \\
\hline Boco & Bocoa prouacensis & 1.109 & 55.2 & 53.0 & 108.9 & 6.9 & 12.1 & 43 \\
\hline
\end{tabular}

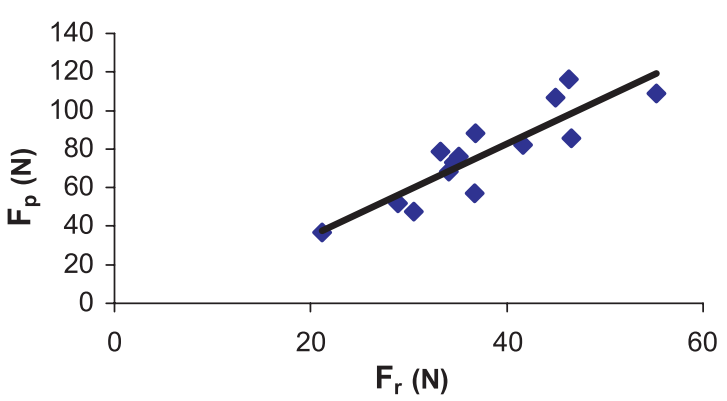

Figure 8. Relation between cutting forces obtained on router and on pendulum.

a problem for us; because the aim of piezo-electric sensors used, is only to confirm results simply obtained with arm rising.

x Influence of arm weight: no tests were done on this factor because of results found in literature [21]. The arm weight does not have any influence on chip formation and cutting forces involved (the gravity center is almost at the arm tip).

\subsection{The pendulum: results and comparisons}

$\times$ The first results obtained were concerned with the relation between cutting forces measured on router $\left(F_{\mathrm{r}}\right)$ and cutting forces measured on pendulum $\left(F_{\mathrm{p}}\right)$. A linear correlation was obtained (Fig. 8) between these two parameters, with a good coefficient of determination: $R^{2}=0.78$.

Thus, it is possible, more easily than with actual tests and formulations [9], to know from a simple test on pendulum, the power demand of wood during machining (taking into account wood material influence, impacts, cutting speed, etc.). x In order to compare values obtained, each calculated cutting forces (on router and on pendulum) was divided by the removed chip volume calculated with mean chip thickness and dimensions of each specimen described previously. All results are presented in Table I.

Different parameters used are: $S G=$ Specific Gravity; $F_{\mathrm{p}}$ is the mean cutting forces measured on pendulum; $F_{\mathrm{r}}$ is the mean cutting forces measured on routers; $F_{[6]}$ is the mean cutting forces obtained with new formulation (Eq. (6)); $V_{\mathrm{r}}$ is the removed chip volume during routing; $V_{\text {pend }}$ is the removed chip volume with pendulum. There are clearly some differences between measured values, with discrepancies of more than $50 \%$ between router (reality) and pendulum values for some wood species. Nevertheless, it is something very easily explainable, mainly by two reasons:

- Firstly, in the case of pendulum (Fig. 4), there are some frictions on tooth lateral sides, whereas it is not the case in routing where cutting process is done only with the side of tools edge and never with the top;

- Secondly, chip formation is different: with pendulum there is formation of a continuous chip (constant chip thickness, close to Franz chip type I), whereas it is not the case in rotating cut like routing (close to Franz chip type II).

However, even if values can not be directly measured, pendulum testing provides a sufficiently and accurate estimate of cutting forces involved during routing. The regression equation from Figure 8 is:

$$
\begin{gathered}
F_{\mathrm{r}}=0,42 . F_{\mathrm{p}}+5.48 \\
R^{2}=0.78
\end{gathered}
$$

where $F \mathrm{p}$ is the cutting forces involved during routing.

In comparison with models used to estimate cutting forces in routing [8], there is an improvement of more than $25 \%$ in 


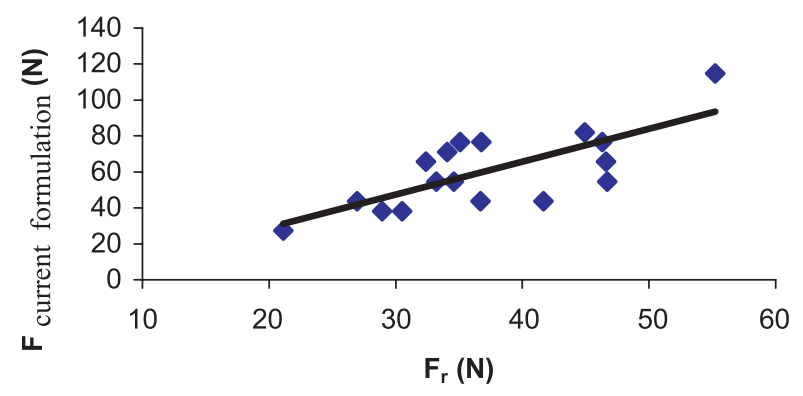

Figure 9. Relation between cutting forces obtained on router and with one of current formulations [8].

precision, and better representation of wood material influences (wood characteristics, anatomy, ...).

Then, in comparison with the first method obtained with mechanical properties (Eq. (6)), the dynamometric pendulum is a valuable means, very simple and cheap (not requiring expensive electronic instrumentations), to predict wood behaviour and cutting forces involved, taking into account the influence of:

- Wood species and wood properties: very important factor as described in the previous work;

- Cutting conditions: velocity, chip thickness, tool's angles, etc.;

- Impacts: very important in machining and responsible for cracking behind the cutting edge.

It is a very good representation of reality, and a good way to obtain indications and results on the influence of many parameters in machining (it could be adapted for other kinds of machining such as sawing or peeling).

A verification of these results was performed on three other species: Movinghi (Distemonanthus benthamianus), Ash (Fraxinus excelsior) and Spruce (Picea sp.). Similar mechanical properties and machining tests were carried out, and allowed to validate these correlations [8]. This provided validation for Movinghi and Ash; but application to Spruce was less successful. Nowadays, it is something already explained with wood anatomy in a previous work [7].

A comparison between results obtained with pendulum (Fig. 8), and results obtained with one of current formulations (using specific gravity to describe wood material influence, Fig. 9), can be done with an improvement of $20 \%$ of the determination coefficient (respectively from 0.54 to 0.78 ).

\section{CONCLUSION}

Following on investigation of wood material influence and mechanical solicitations involved during routing, the aim was to know if an other method, more simple, cheaper and easily adaptable could give the same (or better) results: the dynamometric pendulum.

Results obtained were favourable. The pendulum proved to be a good and practical means to assess cutting properties of new wood species or when new conditions are to be used. Moreover, it allowed taking into account a lot of parameters dif- ficult to study before: impacts, cutting speed, etc. It is very important for wood laboratories and wood industries to have the possibility to, simply and quickly, characterize new wood species or new wood composites in order to find optimal cutting conditions. This is more and more often required because of higher customer requirements and competition. Also, there is a need to use costly high-production machines such as routers more efficiently.

This method opens new perspectives for further developments impossible to contemplate simply before. In the future, a smaller pendulum, more convenient should be studied; and standards could be developed like for hardness or compression, to translate wood cutting strength more accurately.

Acknowledgements: Special thanks to W.M. McKenzie for his advice, and his help in the achievement of this work. We would also like to thank the Cirad forest for funding experimental tropical wood, and all the staff of ENSAM - Cluny, for their help in the achievement of pendulum tests.

\section{REFERENCES}

[1] Aguilera A., Optimisation des conditions de coupe pour l'usinage du bois, Thèse de l'Univ. Henri Poincaré de Nancy I, 2000

[2] Bardet S., Beauchêne J., Thibaut B., Influence of basic density and temperature on mechanical properties perpendicular to grain of ten wood tropical species, Ann. For. Sci. 60 (2003) 49-59.

[3] Beauchêne J., Évolution du comportement mécanique du bois vert avec la température - application à l'étude du déroulage et du tranchage de quelques bois Guyanais, Thèse présentée à l'ENGREF, 1996.

[4] Chardin A., Utilisation du pendule dynamométrique dans les recherches sur le sciage des bois, Rev. Bois For. Trop. 58 (1958) 49-61.

[5] Costes J.F., Approche de l'usinage à grande vitesse du bois : application au défonçage, Thèse de l'université de Toulouse III, 2001, $141 \mathrm{p}$.

[6] CTBA., État de l'art et évolutions des performances des machines d'usinage du bois travaillant par enlèvement de copeau, 1991.

[7] Eyma F., Influence des caractéristiques physiques et mécaniques du bois sur l'usinage, Rapport de DEA Sciences du bois, Univ. Nancy I, 1999.

[8] Eyma F., Caractérisation des efforts de coupe de différentes essences de bois à l'aide de leurs paramètres mécaniques, thèse de l'Univ. Henri Poincaré Nancy I, 2002.

[9] Eyma F., Méausoone P.J., Martin P., Study of the properties of thirteen tropical wood species to improve the prediction of cutting forces in mode B, Ann. For. Sci. 61 (2004) 55-64.

[10] Fischer R., Wood cutting simulation - A program to experiment without a machine, in: Proc. of the 14th Int. Wood Mach. Sem. 1999, pp. 553-562.

[11] Franz N.C., An analysis of the wood-cutting process, Univ. of Michigan Press, Ann. Arbor. Mich., 1958.

[12] Gonçalves M.T.T., Rodrigues R., Takahashi J.S.I., An experimental analysis of the influences of machining conditions on the parallel cutting force in orthogonal cutting for ten Brazilian wood species, in: Proc. of the 13th Int. Wood Mach. Sem., 1997, pp. 481-487.

[13] Huang Y.-S., Hayashi D., Basic analysis of mechanism in woodcutting. Stress analysis in orthogonal cutting parallel to grain, Mok. Gak. 119 (1973) 7-12.

[14] Kivimaa E., Cutting force in wood working, Helsinki, 1950. 
[15] Koch P., Wood machining process, Cambridge, Ronald press, 1964.

[16] McKenzie W.M., Fundamental analysis of the wood cutting process, thesis of the dept. of wood tech., school of natural resources, Univ. Michigan, Ann. Arbor., 1961.

[17] McKenzie W.M., Cowling R.L. A factorial experiment in transverse-plane (90/90) cutting of wood - Part I; Cutting force and edge wear, Wood Sci. 3 (1971) 204-213.

[18] Méausoone P.J., Aguilera A., Martin P., Choice of optimal conditions in wood machining using the "Coupled Tool-Material" method, in: Proc. of the 15th Int. Wood Mach. Sem., 2001, pp. $37-47$.

[19] Merchant M.E., Mechanics of the metal cutting process (I) - orthogonal cutting and a type II chip, J. Appl. Phys. 16 (1945) 267-275.
[20] Noguchi M., Sugihara H., Matsuyoshi R., Studies on Wood Cutting with a Pendulum Dynamometer (V) - Effect of moisture content Wood Res. 34, 1965.

[21] Noguchi M., Sugihara H., Okushima S., Nomura K., Studies on Wood Cutting with a Pendulum Dynamometer (VI) - Relation among Cutting Energy, Cutting Force and Type of Chip Formation, Wood Res. 39, 1966.

[22] Orlenko L., Orlenko E., Making the mathematical model of the wood cutting process, in: Proc. of the 14th Int. Wood Mach. Sem., 1999, pp. 719-723.

[23] Reineke, Sawteeth in action, in Proc. of FPRS, Madison, 1951.

[24] Stewart H.A., Chip formation when orthogonally cutting wood against the grain, Wood Sci. 3 (1971) 193-203.

[25] Sugihara H., Noguchi M., Studies on Wood Cutting with a Pendulum Dynamometer (I), Wood Res. 28 (1962) 31. 